\title{
Choking due to fruit drink aspiration
}

\author{
Luv Sharma*, Basant Lal Sirohiwal, Pramod Kumar Paliwal
}

Department of Forensic Medicine, University of Health Sciences, Rohtak, India; *Corresponding Author: drluvksharma@yahoo.com

Received 23 November 2012; revised 26 December 2012; accepted 5 January 2013

\begin{abstract}
A case of a fatal foreign material aspiration is presented in the following paper. During the autopsy, an orange colored mucus plug was noted in the trachea, which was completely occluding the lumen from mid-level downwards causing a lethal respiratory insufficiency. The bio-chemical and chemical analysis was positive for fructose; there was history of intake of a mango fruit drink just before induction for surgery. The anatomo-pathological exam of the lungs showed the signs of acute asphyxia (Microscopic examinations revealed atelectasia, emphysema, eosinophilic exudate and empty spaces). This case represents a rare lethal event related to the aspiration of a fruit drink in a child just prior to induction.
\end{abstract}

Keywords: Lethal Asphyxia; Complete Laryngeal Obstruction; Choking; Fruit Drink

\section{INTRODUCTION}

Asphyxia, by definition and bearings is a complex term. A foreign body is an acute life-threatening condition [1] and is under-reported as a cause of airway obstruction [2]. Diagnosis based on autopsy findings is difficult as signs and symptoms on the body are mostly vague and non-specific [3]. Majority of such asphyxial deaths are caused by undigested food/other foreign bodies especially in children, the old and the infirm. Conditions that depress the central nervous system, cause coma or depress the gag reflex such as alcohol, narcotics, barbiturates or benzodiazepines increase the likelihood of aspiration and choking [4]. The severity of the complications of foreign body aspiration depends on size, shape, composition, location and orientation of the aspirated object Delay in treatment can result in obstructive emphysema, localized bronchoectasis, atelectasis, oedema and collapse [5]. The diagnosis of death by choking is based on the detection of the generic signs of asphyxia, on the identification of the foreign body obstructing the airways and on the exclusion of other causes of death.
The case here reported regards a rare case of complete obstruction of the trachea by a mucous plug formed due to the accidental aspiration of a fruit drink just after preop induction.

\section{CASE REPORT}

\subsection{Case History}

A case report of a rare sudden death of a previously healthy 13-year-old girl is examined. The deceased was due for a planned femoral hernia operation and kept N.P.O. She suddenly presented with acute respiratory distress on pre-op induction and collapsed. Despite resuscitative efforts, the patient died within a few hours. The patient's family admitted giving the child a sip of a mango fruit drink just prior to induction as she was complaining of thirst.

\subsection{Autopsy Findings}

The lungs were distended and over-inflated, whose compression showed crackling and leaking of frothy hematic liquid; numerous sub-pleural and sub-epicardial petechiae were also perceptible. Asphyxial petechiae were perceptible on the lung surface. Dissection of the trachea revealed an orange colored mucous plug, in a frothy pool occluding the lumen (Figures 1 and 2).

\subsection{Histological Findings}

Lung tissues for light microscopic examinations were fixed in $10 \%(\mathrm{w} / \mathrm{w})$ neutral buffered formaldehyde solution and stained with hematoxylin-eosin. The histological exam of the lung samples revealed massive emphysematous areas with rupture of the septa, alternated with peribronchial alveoli plugged by erythrocytes and emosiderophage hystiocytes; abundant cellular debris, constituted by degenerated lining epithelium and mucous, were noticed in the bronchial and bronchiolar terminal branches.

\subsection{Toxicological Analysis}

The analyses were performed on blood and urine samples collected during the autopsy; the toxicological 


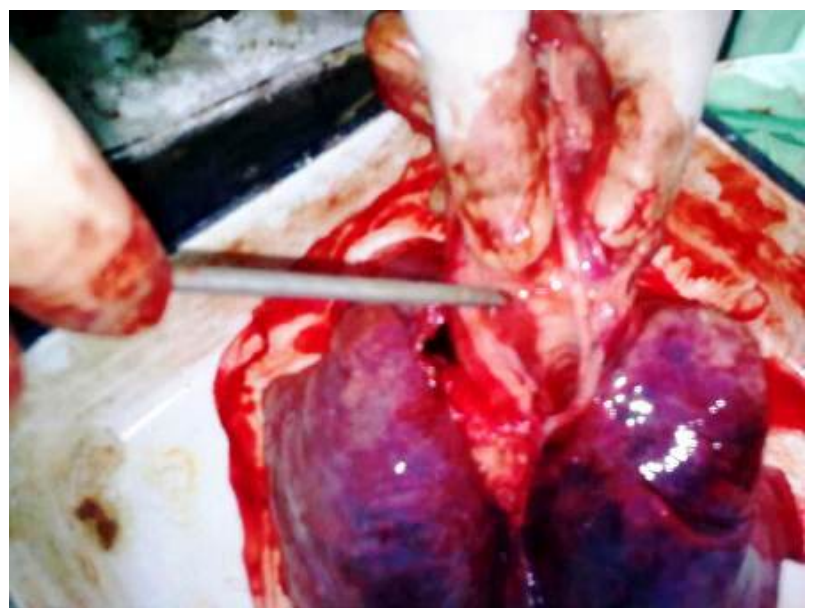

Figure 1. Orange colored mucus pug completely occluding the tracheal lumen from midlevel.

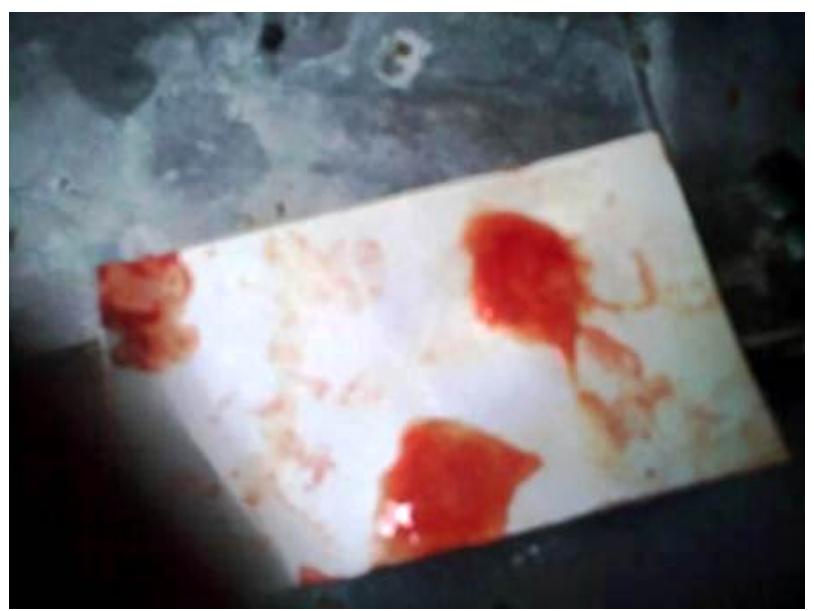

Figure 2. The mucus plug on a filter paper after removal from trachea.

results were negative for psychotropic, antidepressants and sedatives drugs, as well as for other organic nitrogen toxic xenobiotics. The search for ethylic alcohol and other volatile organic solvents (i.e.: ethylic ether, chloroform, petrol, etc.) was negative too.

\subsection{Bio-Chemical Tests}

Bio-chemical analysis of mucus plug was positive for Fructose glucose sucrose (Fructose-Glucose) and other sugars.

\section{DISCUSSION}

Inhalation of foreign body into the tracheobronchial tree is a medical emergency sometimes resulting into sudden death. The current mortality rate due to foreign body inhalation ranges from $0 \%$ to $1.8 \%$ [6]. As well known; choking is a form of mechanical asphyxia caused by the aspiration of a foreign body able to obstruct the airways. Choking can be defined as typical or atypical depending on the capacity of the foreign body to completely or partially occlude the airways, respectively [7]. The typical form of choking is generally caused by any object able to adapt and completely obstruct the air passage (i.e.: meat or vegetable food, etc.). In the atypical form of choking, the foreign body is characterized by a well-defined shape (i.e.: buttons, coins, balls, etc.), not necessarily correspondent to the airways profile and often not able to obstruct it completely. In both cases, the spasm of the larynx contributes to the asphyxial mechanism [8]. When a complete obstruction occurs, the external resuscitation techniques may be useless, being unable to ventilate the lungs. Only once the foreign body has been removed, a rapid intubation allows pulmonary ventilation, whilst the obstruction at laryngeal level may be treated only by a prompt tracheotomy. Anyway, the timing of care intervention must be very quick, because irreversible brain damage or death may occur even 5 - 10 minutes after a lesion the beginning of mechanical obstruction [9-13].

Berzlanovich et al., in an autopsy based study, demonstrated that semisolid foods were the cause of a large number of asphyxiations, especially among the elderly, while in contrast, younger individuals choked significantly more often on large pieces of foreign material [14].

Prevention and early recognition remain critical factors in the treatment of foreign body inhalation and ingestion in children. Accidental inhalation or ingestion of both organic and non-organic foreign body material continues to be a cause of childhood morbidity and mortality. The diagnosis of foreign body aspiration may easily be missed. An unusual case of foreign body ingestion in a child is presented. A 2 years old female patient was a fibro optic bronchoscopy showed a popcorn kernel in her right main bronchus. The first known fatality attributed to aspiration is said to be the Greek poet Anacreon who died in 475 BC after aspirating a grape seed. Sir James Y. Simpson attributed the first well documented anesthesia related death in 1848. A significant advancement in bronchoscopy was achieved by introduction of Hopkins telescope in 1976 [15].

Qureshi et al. report 3 cases of aspiration of a popular fruit-flavored gel snack leading to cardiopulmonary arrest and death in 1 case and respiratory failure in 2 other cases. They commented that items lodged in the oral cavity, hypopharynx, or larynx can produce airway obstruction leading to hypoxia, respiratory failure, or even cardiac arrest. However, most items pass through the larynx and become lodged in the trachea or main stem bronchus [16].

The longer a foreign body resides in the airway, the more likely it is to migrate distally. When this occurs, symptoms of chronic cough and wheezing may mimic an 
asthma-like condition [17].

The aspired foreign material being a liquid did not occlude the whole extent of the trachea initially, but excessive salivation in the inner air passages admixed with mucus led to formation of the plug eventually occluding the tracheal lumen. Usually an individual can easily make movements in the internal airway between the pharynx and the bifurcation of the trachea in order to expel the foreign body. However, lulling of the gag reflex due to pre-anesthetic medications led to fatal choking.

\section{REFERENCES}

[1] Blaschke, U. and Cheng, E.Y. (1989) Foreign body in upper airway. Unsuspected cause of obstruction. Postgraduate Medicine, 86, 235-237.

[2] Casson, A.G. and Guy, J.R. (1998) Foreign-body aspiration in adults. Canadian Journal of Surgery, 30, 193-194.

[3] Lai, Y.F., Wong, S.L., Chao, T.Y. and Lin, A.S. (1996) Bronchial foreign bodies in adults. Journal of the Formosan Medical Association, 95, 213-217.

[4] Munter, D.W. (2001) Foreign bodies, trachea. Emergency Medicine Journal, 2, 28.

[5] Warshawsky, E.M. (2003) Foreign body aspiration. Emergency Medicine Journal, 3.

[6] Sinha, V., Memon, R., Gupta, D., Prajapati, B., Bhat, V. and Yogesh, M. (2007) Foreign body in tracheobronchial tree. Indian Journal of Otolaryngology and Head \& Neck Surgery, 59, 211-214. doi:10.1007/s12070-007-0063-9

[7] Barbera, N., Arcifa, V., Valenti, V., Spadaro, G., Tomasello, S. and Romano, G. (2012) Fatal asphyxia by complete laryngeal obstruction due to chewing-gum aspiration in an adult woman-Case Report. Romanian Journal of Legal Medicine, 20, 33-36. doi:10.4323/rjlm.2012.33

[8] Arbarello, P., Di Luca, N.M., Feola, T. and Macchiarelli,
L. (2005) Medicina Legale. 2nd Edition, Minerva Medica, Torino, 343-345.

[9] Njau, S.N. (2004) Adult sudden death caused by aspiration of chewing gum. Forensic Science International, 139, 103-106. doi:10.1016/j.forsciint.2003.09.021

[10] Berzlanovich, M.A., Manfred, M., Sim, E. and Bauer, G. (1999) Foreign body asphyxiation-An autopsy study. American Journal of Medicine, 107, 351-355. doi:10.1016/S0002-9343(99)00242-9

[11] Donato, L., Weiss, L., Bing, J. and Schwarz, E. (2000) Tracheobronchial foreign bodies. Archives de Pédiatrie, 7, 56s-61s. doi:10.1016/S0929-693X(00)88821-1

[12] Kitay, G. and Shafer, N. (1989) Café coronary: Recognition. Nurse Practitioner, 14, 35-46. doi:10.1097/00006205-198906000-00004

[13] Eller, W.C. and Haugen, R. (1973) Food asphyxiationrestaurant rescue. New England Journal of Medicine, 289, 81-82. doi:10.1056/NEJM197307122890206

[14] Berzlanovich, A.M., Fazeny-Dörner, B., Waldhoer, T., Fasching, P. and Keil, W. (2005) Foreign body asphyxia: A preventable cause of death in the elderly. American Journal of Preventive Medicine, 28, 65-69. doi:10.1016/S0749-3797(04)00077-7

[15] Deepak, H., Vaidiyanathan, S., Ranganath, A.K., Patel, A.K. and Gupta, R. (2008) Asymptomatic foreign body aspiration in a child. Internet Journal of Anesthesiology, 17.

http://www.ispub.com/journal/the-internet-journal-of-ane sthesiology/volume-17-number-1/asymptomatic-foreignbody-aspiration-in-a-child.html\#sthash.MLZCK7Y1.dpuf

[16] Qureshi, S. and Mink, R. (2003) Aspiration of fruit gel snacks. Experience and reason. Pediatrics, 111, 687-689. doi:10.1542/peds.111.3.687

[17] Swanson, K.L. and Edell, E.S. (2001) Tracheobronchial foreign bodies. Chest Surgery Clinics of North America, 11, 861-872. 